\title{
ATELIÊ DE TEXTOS: (RE)INVENÇÃO E (RE)ESCRITA DE HISTÓRIAS NO ENSINO BÁSICO*
}

\section{ATELIÊ DE TEXTOS: (RE)INVENTING AND (RE)WRITING STORIES IN ELEMENTARY SCHOOL}

\author{
Cristiane Fuzer**
}

RESUMO: Neste artigo, apresentamos uma sistematização do processo de produção de textos narrativos, decorrente de análises das práticas de leitura e escrita desenvolvidas com alunos das séries finais do ensino fundamental em quatro escolas públicas ao longo de três anos. Para o encaminhamento das atividades e, posteriormente, das análises que culminaram no percurso metodológico, são utilizados subsídios das abordagens sociorretórica e sistêmico-funcional. Em três etapas gerais - pré-escrita, (re)escrita e pós-escrita -, são propostas atividades que, em sequência, auxiliam na produção de versões cada vez mais semelhantes ao gênero de referência e contribuem para a descoberta de motivações pessoais para aprender a escrever.

PALAVRAS-CHAVE: Escrita. Processo. Gênero narrativa. Ensino.

ABSTRACT: In this paper, we present a systematization of the production process of narrative texts, resulting from the analyses of reading and writing practices developed with students of the upper grades of elementary school in four public schools over three years. In order to carry out the activities and the analyses that culminated in the methodological approach, subsidies of socio-rhetorical and systemic functional approaches are used. Based on three general stages - prewriting, (re)writing and post-writing - we proposed sequential activities that assist in the production of versions increasingly more similar to the reference genre and contribute to the discovery of personal motivations to learn writing.

KEYWORDS: Writing. Process. Narrative genre. Teaching.

\footnotetext{
* Trabalho resultante de projeto de ensino e extensão com apoio do PROLICEN (Programa de Licenciaturas) e FIEX (Fundo de Incentivo à Extensão) da UFSM. Agradeço a Angela Maria Rossi, Carla Carine Gerhard, Elisane Scapin Cargnin, Letícia Oliveira de Lima, Rochele Perosa, Sabrine Weber e Taciane Weber a fundamental colaboração nas atividades desenvolvidas no Ateliê de Textos, as quais embasam as reflexões e a sistematização do percurso metodológico do ensino de escrita como processo aqui proposto. $\mathrm{O}$ conteúdo deste artigo, entretanto, é de minha inteira responsabilidade.
} 


\section{ATELIÊ DE TEXTOS: (RE)INVENÇÃO E (RE)ESCRITA DE HISTÓRIAS NO ENSINO BÁSICO}

\section{INTRODUÇÃO}

Pelas definições lexicográficas, ateliê é o "local onde artesãos ou operários trabalham em conjunto, numa mesma obra"; "grupo de artistas, assistentes e aprendizes que trabalham sob a direção de um mestre artista ou artesão" (HOUAISS, 2001, p.332) ou ainda "aula ou curso prático sobre uma atividade ou um assunto específico" (PRIBERAM DA LÍNGUA PORTUGUESA, 2008-2013 online).

No Ateliê de Textos aqui referido, os artesãos são jovens que, com a assistência de um mediador, produzem textos para compor sua obra: uma coletânea de contos reinventados em que se funde um imaginário fantástico com sonhos reais, valores e desejos de adolescentes contemporâneos. Assim podem ser resumidos o processo (que envolve atividades de leitura, escrita e reescrita de textos por alunos do ensino básico) e o produto decorrente do projeto que, em 2013, foi contemplado com o Prêmio RBS de Educação na categoria projeto comunitário ${ }^{1}$.

O Ateliê de Textos, como é conhecido nas escolas parceiras, é o nome dado às oficinas de leitura e produção textual vinculadas ao projeto "Práticas orientadoras para o processo de produção e avaliação de textos" (GAP/CAL/UFSM 029622), que tem por objetivo promover e sistematizar procedimentos para conduzir o processo ensinoaprendizagem de leitura e produção de textos de alunos do ensino básico, numa perspectiva textual-interativa. Buscamos não apenas oferecer uma atividade extra e prazerosa com a leitura e a escrita para alunos do ensino básico em escolas públicas que

\footnotetext{
${ }^{1}$ O Prêmio RBS de Educação é uma iniciativa do Grupo RBS (Rede Brasil Sul de telecomunicações) e da Fundação Maurício Sirotsky Sobrinho, realizado com assessoria técnica do Centro de Estudos e Pesquisas em Educação, Cultura e Ação Comunitária (Cenpec). Na edição 2013, o Prêmio fundamentouse em princípios divulgados pelo Ministério da Educação, com o objetivo de "mobilizar professores e pessoas interessadas em estimular ações de incentivo à leitura a refletir sobre as práticas de mediação que vêm exercendo e aprimorá-las” (PRÊMIO RBS DE EDUCAÇÃO, 2013).
} 
buscam qualificar saberes linguísticos, mas também lhes oportunizar o sentimento de esforço reconhecido a partir da socialização dos textos para além dos limites da sala de aula e da escola. Até o momento, quatro edições do Ateliê de Textos já foram realizadas. A partir de análises e reflexões sobre os processos de produção escrita desenvolvidos nessas oficinas, foram sistematizadas estratégias para melhor organizar as atividades e otimizar o uso de recursos didáticos ao longo do processo. Um dos recursos é o bilhete orientador, gênero catalisador considerado eficaz por diversos pesquisadores (BUIN, 2006; SIGNORINI, 2006; PENTEADO e MESKO, 2006; GONÇALVES e BAZARIN, 2009; RUIZ, 2010; NASCIMENTO, 2013) para o ensino de produção textual, mas sem um tratamento analítico e descritivo de sua organização retórica.

Diante dessa situação, propomos, em trabalhos anteriores, uma sistematização de movimentos e passos que organizam o bilhete orientador como um gênero (FUZER, 2012), possibilitada pelo levantamento de padrões linguísticos usados para estabelecer interação com o aluno-escritor. Além disso, demonstramos as implicações de bilhetes orientadores na reescrita de textos, como parte de uma proposta de ensino de produção textual que viabiliza a interação professor e aluno via texto (FUZER e WEBER, 2012).

Ambos os trabalhos tiveram o propósito de auxiliar professores a utilizarem adequadamente esse recurso didático nas aulas de produção textual.

Tendo ainda em mente esse propósito, somado à necessidade de avançarmos na reflexão sobre metodologias de ensino e aprendizagem da escrita, temos por objetivo, neste artigo, propor uma sistematização do processo de produção textual organizado em etapas que ajudem o aluno a fazer seus textos terem vida para leitores a distância. Temos como premissa que, "criando interação dos significados evocados pelo texto", o aluno-autor terá alcançado "a agência mais profunda da escrita" (BAZERMAN, 2006, p.21), aprendendo a escolher recursos disponíveis no sistema linguístico para melhor atender aos seus propósitos de comunicação e interação social.

Focaliza-se, neste trabalho, a produção escrita como processo em que habilidades linguísticas são desenvolvidas por meio do engajamento em atividades socialmente compartilhadas, como prevê a perspectiva sociorretórica da linguagem (BAZERMAN, 2006; MILLER, 1984) e a visão sociointeracionista da aprendizagem (VYGOTSKY, 1991; FEUERSTEIN, 1990). Também se focaliza o texto como um processo e um produto, conforme a teoria sistêmico-funcional (HALLIDAY, 1994; HALLIDAY e MATTHIESSEN, 2004 e 2014).

No que se refere ao trabalho com a escrita, isso significa trabalhar o texto como processo que vai sendo qualificado pelo próprio aluno-autor à medida que interações com outros leitores (colegas, professores e estudantes de Letras no caso do Ateliê de Textos) vão fornecendo feedbacks que orientam a reescrita e colaboram para se chegar a um produto (neste caso, uma coletânea de contos reinventados) a ser compartilhado com a comunidade.

Para demonstrar o funcionamento desse processo, este texto está organizado em três seções, além desta Introdução e das Considerações Finais. Na primeira seção, são revisadas bases teórico-metodológicas que norteiam nosso olhar sobre a linguagem, o texto e a prática de produção escrita. Na segunda seção, são apresentados o universo de análise em que se desenvolveram práticas de ensino que suscitaram reflexões e a elaboração de um percurso metodológico para o trabalho com a produção de textos no ensino básico, proposta que está delineada na terceira seção. 


\section{BASES TEÓRICO-METODOLÓGICAS DA PROPOSTA}

Nesta seção, apresentamos noções de linguagem, texto, gênero textual e processo de escrita com base em pressupostos teóricos que consideramos pertinentes à proposta metodológica de ensino da escrita que delineamos a partir das ações desenvolvidas no âmbito do projeto a que se vinculam as edições do Ateliê de Textos nas escolas. Iniciamos pelo ponto de vista social da escrita, conforme a abordagem sociorretórica; a seguir, enfatizamos a associação do caráter social com o semântico e léxico-gramatical, de acordo com a abordagem sistêmico-funcional; por fim, apresentamos o caráter processual da escrita no contexto escolar, considerando a perspectiva textual-interativa.

\subsection{A escrita como ação social: perspectiva sociorretórica}

Aspectos contextuais da linguagem são o foco da abordagem sociorretórica, na qual os textos "são atos de nossa vontade" e a escrita "nos ajuda a tornar real e forte nossa presença num mundo social em que asseveramos nossas necessidades e nosso valor" (BAZERMAN, 2006, p.13). Enfatizam-se aspectos da dinamicidade, da fluidez e da heterogeneidade dos gêneros, vistos como "ações retóricas tipificadas", nos termos de Miller (1984).

Especialmente voltados para contextos acadêmicos e profissionais, estudos sociorretóricos consideram que as situações sociais permitem ou impõem determinadas formas de comunicação e ação, focalizando aspectos pragmáticos da linguagem. Ações tipificadas são realizadas por meio da linguagem em funcionamento nos gêneros (MILLER, 1084; BAZERMAN, 2005; FREEDMAN e MEDWAY, 1994). O enfoque está, portanto, mais nas categorias etnográficas do discurso e na ação que este realizará e menos na sua substância ou forma (MILLER, 1984).

Apesar de essas noções terem advindo de um olhar sobre a linguagem usada em contextos institucionais que demandam certa previsibilidade de ações, a ideia de gênero como ação social é útil aos propósitos pedagógicos no contexto escolar no que se refere à motivação e, por conseguinte, ao reconhecimento de um sentido para o texto a ser escrito. Mediante o estabelecimento de um motivo, uma necessidade ou um desejo, o aluno se vê envolvido numa situação real de comunicação, podendo escolher situações e temas que tenham correspondência com seus interesses e com seu dia a dia (PASSARELLI, 2012). Como argumenta Bazerman (2006, p.34),

\footnotetext{
uma vez que os alunos se sintam parte da vida de um gênero, qualquer um que atraia sua atenção, o trabalho duro e detalhista da escrever se torna irresistivelmente real, pois o trabalho traz uma recompensa real quando engajado em atividades que os alunos consideram importantes.
}

Dessa forma, é importante o professor propiciar ao aluno a escolha de um gênero que possibilite alcançar determinado objetivo numa situação real, o pode motivar o aprendiz a se empenhar no processo de produção de um texto adequado a tal situação.

Outro motivo significativo para a escrita no contexto escolar se refere ao papel que a escola exerce no desenvolvimento pessoal e intelectual de jovens e crianças, ao "estimular as emoções, o pensamento e a imaginação" (BAZERMAN, 2006, p.16). É sob esse enfoque que as propostas de produção de textos narrativos são elaboradas no 
Ateliê de Textos, conforme veremos na seção 3. Cabe aos professores, segundo Bazerman (2006), manter vivos, em ações significativas da comunicação escolar e fora dela, os gêneros que solicitam aos alunos produzirem. Para o autor, a escolha estratégia de gêneros pode auxiliar a introduzir o aluno "em novos territórios discursivos, um pouco mais além dos limites de seu habitat linguístico" (BAZERMAN, 2006, p.31).

Entretanto, Gonçalves e Bazarin (2013, p.12) acreditam que não o gênero em si que garantirá a aprendizagem de determinadas habilidades, mas sim "a forma como o processo de ensino-aprendizagem é organizado e monitorado pelo professor". Tendo por base a noção de gêneros como "megainstrumentos" (SHNEUWLY, 2004), as autoras argumentam que "o que está em jogo não é a relevância social do gênero, mas as habilidades de leitura/escrita que os alunos poderão aprender nos/através dos diferentes gêneros" (GONÇALVES e BAZARIN, 2013, p.12).

Compartilhamos parcialmente desta posição, uma vez que entendemos aspectos sociais e linguísticos inerentes à natureza da linguagem. Se determinados propósitos sociocomunicativos podem ser alcançados mediante a escolha de um gênero textual pertinente ao contexto compartilhado entre o produtor do texto e sua audiência em potencial, então é importante que seja oferecido ao aluno um contexto em que possam ser articulados "conhecimentos e competências por meio de usos da linguagem em situações específicas, para realizar determinadas atividades sociais" (MOTTAROTH, 2006, p.498).

Nesse sentido, consideramos necessária a associação de ambos os aspectos da escrita: o social e o linguístico, para que se possa envolver o aluno no árduo e complexo processo de produção de textos não apenas como artefatos em que se demonstram o quanto se sabe da estrutura textual e linguística, mas como meios para compartilhar pensamentos, interagir, influenciar, divertir e cooperar, tendo em vista interesses intelectuais e pessoais de quem escreve. O desafio para o professor é articular esses aspectos de modo equilibrado, dando espaço para que os aspectos social e linguístico sejam percebidos como constituintes da linguagem e, por conseguinte, de qualquer texto a ser produzido. Essa associação é cara à teoria sistêmico-funcional, abordada na próxima seção.

\subsection{Aspectos sociais e linguísticos da escrita: perspectiva sistêmico-funcional}

$\mathrm{Na}$ abordagem sistêmico-funcional, a linguagem tem caráter probabilístico, ou seja, é um sistema potencial de significados à disposição dos falantes. A descrição da gramática nessa perspectiva vem sendo desenvolvida desde a década de 1950, em uma vasta gama de publicações e sistematizada na obra An introduction to funcional grammar (1985, 1994), revisitada e ampliada por Halliday com a colaboração de Matthiessen $(2004,2014)$. É uma gramática funcional porque busca explicar como funciona a linguagem em contexto e reconhece que são os usos dos falantes que, de geração em geração, têm configurado o sistema linguístico (HALLIDAY, 1998).

As análises dos gêneros e registros estão centradas nos textos como evidências do discurso de uma sociedade ou de uma cultura. O texto é concebido como o resultado das escolhas dos falantes no âmbito das opções disponibilizadas no sistema linguístico, organizado em estratos inter-relacionados: fônico-gráfico, léxico-gramatical, semântico e contextual.

Texto e contexto estão inter-relacionados, de modo que o texto reflete influências do contexto em que é produzido, na medida em que as variáveis do contexto 
de situação atuam sobre a sua configuração linguística (EGGINS, 1994). Nas palavras de Halliday (2007, p.16), "certo tipo de linguagem é apropriada para certo uso".

As análises que se realizam nessa perspectiva teórica se propõem a mostrar "como e por que um texto significa o que significa" (WEBSTER, 2009, p.7), buscandose identificar as estruturas de linguagem específica que contribuem para o significado dos textos na interface com o contexto situacional (que determina o registro) e cultural (valores, crenças, ideologias) em que está inserido.

Texto é, portanto, concebido como produto e como processo simultaneamente (HALLIDAY e HASAN, 1989). É "produto sociossemiótico orientador e revelador das atividades interacionais cotidianas" (SILVA e ESPINDOLA, 2013, p.267), permitindo o estudo de sua materialidade linguística. $O$ texto também é processo por representar eventos em que ocorrem trocas de significados entre os participantes da interação, numa rede de significados potenciais disponíveis para serem usados conforme as necessidades de interação e representação de experiências.

A partir dessa perspectiva de linguagem e texto, gênero, localizado no contexto de cultura, é definido por Martin e Rose (2007, p.8) como um "processo social organizado por estágios e orientado para propósitos sociais",2. Segundo os autores, é social porque "participamos da elaboração do gênero coletivamente"; é organizado por estágios porque "normalmente o gênero demanda-nos etapas para alcançarmos nossos objetivos", e é orientado para objetivos porque "utilizamos gênero para pôr coisas em prática"3 (MARTIN e ROSE, 2007). Verifica-se, assim, a íntima associação entre o caráter social e linguístico do gênero na perspectiva sistêmico-funcional, o que consideramos fundamental no planejamento de atividades a nortearem um processo de produção escrita em sala de aula. Nos termos da Pedagogia de Gêneros, derivada da teoria sistêmico-funcional que ficou conhecida como Escola de Sidney ${ }^{4}$, os gêneros são agrupados de acordo com o propósito sociocomunicativo que compartilham. No processo de leitura e escrita desenvolvido no Ateliê de Textos, um dos gêneros produzidos pelos participantes é a narrativa, cujas características gerais são apresentadas na seção a seguir.

\subsection{0 gênero narrativa na perspectiva da escola de sidney}

O foco da pedagogia baseada em gêneros da Escola de Sidney é "a preparação de todos os estudantes para ler textos do currículo e usar o que aprenderam da leitura em sua própria escrita" (ROSE e MARTIN, 2012, p.308). Para Gouveia (2013, p.8), um ensino baseado em gêneros

\footnotetext{
${ }^{2}$ Tradução nossa de "a staged, goal-oriented social process".

${ }^{3}$ Tradução de Silva e Espindola (2013:281 para "Social because we participate in genres with other people; goal-oriented because we use genres to get things done; staged because it usually takes us a few steps to reach our goals".

${ }^{4}$ O termo "Escola de Sidney" surgiu em 1994 em referência ao trabalho com linguagem e educação realizado no Departamento de Linguística da Universidade de Sidney. O objetivo inicial do projeto era desenvolver uma pedagogia de escrita que permitisse a qualquer estudante ser bem-sucedido nas atividades exigidas pela escola. As estratégias de ensino para guiar os estudantes na escrita de diferentes gêneros ficaram conhecidas como "pedagogia baseada em gêneros", fornecendo conhecimento explícito sobre a linguagem na qual o currículo é elaborado e negociado em sala de aula (ROSE e MARTIN, 2012).
} 
garantirá não só melhores produtores textuais, como também melhores alunos, uma vez que a experiência com os gêneros desenvolve capacidades e habilidades mentais dos alunos e promove a aquisição das estruturas esquemáticas e padrões de linguagem característicos das várias disciplinas.

O gênero narrativa, por exemplo, é comumente usado em diferentes disciplinas curriculares quando o propósito for resolver uma complicação. Assim como o relato, o exemplum, o episódio e a notícia jornalística que compõem o grupo das histórias, a narrativa tem a função de envolver os leitores (ROSE e MARTIN, 2012) (Quadro 1).

Quadro 1 - Gêneros do grupo das histórias (adaptado por Gouveia, 2013, a partir de Rose e Martin, 2012:56).

\begin{tabular}{|l|l|l|l|}
\hline & Gênero & \multicolumn{1}{|c|}{ Objetivo sociocomunicativo } & \multicolumn{1}{c|}{ Estágios } \\
\hline \multirow{2}{*}{ Relato } & Relatar uma série de eventos & $\begin{array}{l}\text { - Orientação } \\
\text { - Rol de eventos }\end{array}$ \\
\cline { 2 - 4 } & \multirow{2}{*}{ Narrativa } & Resolver uma complicação & $\begin{array}{l}\text { - Orientação } \\
\text { - Complicação } \\
\text { - Avaliação } \\
\text { - Resolução }\end{array}$ \\
\cline { 2 - 4 } & \multirow{2}{*}{ Exemplum } & $\begin{array}{l}\text { Apreciar/ajuizar comportamentos (numa } \\
\text { complicação que não é resolvida) }\end{array}$ & $\begin{array}{l}\text { - Orientação } \\
\text { - Complicação } \\
\text { - Avaliação }\end{array}$ \\
\cline { 2 - 5 } & \multirow{2}{*}{ Episódio } & $\begin{array}{l}\text { Compartilhar emoções (numa complicação } \\
\text { que não é resolvida) }\end{array}$ & $\begin{array}{l}\text { - Orientação } \\
\text { - Complicação } \\
\text { - Avaliação }\end{array}$ \\
\hline
\end{tabular}

Quanto à sua organização estrutural, as histórias têm um padrão típico: um estágio de apresentação de protagonistas num tempo e espaços determinados e também uma sequência temporal de acontecimentos, seguida de um fecho. No entanto, os gêneros enquadrados como histórias não se desenvolvem estruturalmente do mesmo modo. $\mathrm{O}$ gênero narrativa se diferencia dos outros gêneros de história por apresentar uma complicação ou adversidade que se coloca aos protagonistas. Além disso, a presença ou não de elementos de avaliação ou de reflexão sobre os eventos da história pode se configurar como fator de distinção entre os gêneros desse grupo (GOUVEIA, 2013).

Com relação às realizações léxico-gramaticais, são típicas do gênero narrativa orações materiais para representar acontecimentos e ações das personagens, orações relacionais para identificar e caracterizar cenários e personagens, orações verbais para introduzir diálogos. Orações existenciais, introduzidas geralmente por "Era uma vez", também são recorrentes em textos desse gênero.

Ao adotarmos a perspectiva de gênero da Escola de Sidney, reconhecemos que o ponto de partida de um trabalho com produção textual deve ser o contexto de uso da

\footnotetext{
${ }^{5}$ Segundo Canton (2009), essa expressão foi usada pela primeira vez pelo francês Charles Perrault, em 1649, no poema "Os Desejos Ridículos", escritos para adultos. Como essa expressão funciona para introduzir histórias, "fazendo soar como se o tempo estivesse suspenso, para criar um clima mágico" (CANTON, 2009:18), o escritor retoma-a no seu primeiro conto de fadas, "Pele de Asno", e passa a usála constantemente em suas histórias.
} 
linguagem, aliado ao trabalho com aspectos léxico-gramaticais, já que, conforme Passarelli (2012, p.124), "recorrer a tais aspectos auxilia na construção dos sentidos". Isso demanda do professor habilidades para estabelecer interações com os alunos sobre diferentes aspectos da linguagem a serem mobilizados para a produção do texto pelo aluno em diferentes etapas do processo, como abordamos na seção a seguir.

\subsection{A escrita como processo e interação}

Em ambas as perspectivas teóricas apresentadas nas seções anteriores, reconhece-se a escrita como um processo complexo e contínuo, em que há finalidades reais para o aluno escrever e são mobilizados diferentes competências tanto do professor como do aluno (GONÇALVES, 2013). Nesse processo, o texto precisa ser compreendido como provisório, sujeito a alterações para que melhor se ajuste ao propósito sociocomunicativo do seu autor. Por isso, a aprendizagem da escrita é considerada um processo que não termina quando finda a produção do texto em sua primeira versão. A primeira versão é ponto de partida para novas versões cada vez mais qualificadas (LEITE e PEREIRA, 2013; NASCIMENTO, 2013; GERALDI, 1993).

Esse enfoque advém da abordagem processual da escrita, em que se destacam o modelo de Hayes e Flower (1981) e o de Scardamalia e Bereiter (1987). No seu modelo de representação do processo cognitivo, Flower e Hayes (1981) reconhecem três processos de geração de texto escrito: a planificação, a textualização e a revisão, que são controlados por um sistema de monitorização ou mediação. A escrita é concebida como uma atividade orientada por propósitos definidos que fazem parte do contexto da tarefa. São consideradas como partes integrantes do processo as informações de natureza contextual, como a consciência do produtor acerca do objetivo do texto, o reconhecimento da relação entre produtor e leitor e a influência do público-alvo.

Scardamalia e Bereiter (1987), por sua vez, conceberam um mecanismo que inclui dois modelos: o relato de conhecimento, acionado por escritores menos proficientes, e a transformação de conhecimento, acionada por escritores mais proficientes em situações diferentes, para solucionar problemas de escrita distintos. É reconhecido, assim, o envolvimento de três aspectos: o papel do público, as diferenças de gênero textual e a consciência da complexidade da tarefa de escrita. É evidenciada, assim, a importância do ensino explícito de características de diversos gêneros textuais para estimular a consciência das convenções de escrita, que têm de ser dominadas para a produção de textos bem formados, adequados ao contexto sociocomunicativo (GRABE e KAPLAN, 1986).

Nessa perspectiva, o texto, tomado como um momento no processo de aprendizagem, precisa ser revisado e reescrito, modificando-se em versões cada mais adequadas ao propósito e à situação comunicativa. Entretanto, como alerta Passarelli (2012), por não terem oportunidade de presenciar o planejamento e a revisão do escritor, tendo acesso apenas ao texto final, os jovens, muitas vezes, têm uma impressão equivocada da atividade de escrita, como uma ação que leva a um produto final em uma única instância de produção ${ }^{6}$. Ao contrário disso, a revisão e a reescrita evidenciam a

\footnotetext{
${ }^{6}$ Segundo, Halliday (1994), para fazer sentido a um texto, a tendência natural das pessoas é pensar um texto como uma coisa - "um produto". Essa postura implica diretamente no modo como tem sido conduzido o ensino de produção de textos na escola, sem oportunidades para revisões criteriosas e reescritas. Quando o professor passa a ver o texto como um processo, a metodologia de ensino de
} 
ideia do texto em progressão, "um produto que dá origem a um novo processo, permitindo uma nova fase na construção do texto" (MENEGASSI, 1998, p.40).

A revisão e a reescrita, na escola, devem ser mediadas por um leitor e produtor de textos mais experiente, o professor, que precisa estar ciente da importância de seus apontamentos e comentários sobre o texto do aluno serem desprovidos de ambiguidades, imprecisões, generalizações, preconceitos e excesso de críticas (SERAFINI, 1998), a fim de que não causem efeito contrário ao pretendido, confundindo ao invés de auxiliar o aprendiz em seu aprendizado da escrita.

Vários pesquisadores apontam a revisão textual-interativa como a mais eficaz para orientar a reescrita pelo aluno (RUIZ, 2010; FUZER e WEBER, 2012; NASCIMENTO, 2013; LEITE e PEREIRA, 2013; MENEGASSI, 2013, dentre outros), uma vez que aluno e professor dialogam por meio de textos sob a forma de bilhetes, visando à qualificação do texto. Por meio desse recurso interativo, o professor pode elogiar os pontos positivos do texto, levar o aluno-autor a refletir sobre determinados aspectos do texto, sugerir ajustes, explicar categorias, instruir sobre recursos linguísticos, incentivar à qualificação textual e ao investimento de energia para prosseguir se empenhando no processo de produção.

Para fins didáticos, o processo de produção textual pode se desenvolver em três etapas gerais: a pré-escrita, a escrita e a pós-escrita (SOARES, 2009).

$\mathrm{Na}$ etapa de pré-escrita, são realizados estudos sobre o gênero textual a ser utilizado, definindo-se um contexto de situação (a atividade a ser realizada, o tema a ser desenvolvido, o objetivo da comunicação, a audiência potencial, o modo de organização da linguagem). Engloba atividades que auxiliem o autor a descobrir maneiras de abordar a tarefa, a identificar ou delinear o contexto, a coletar informações, a gerar ideias. Sob a perspectiva sistêmico-funcional, nessa etapa, o professor leva os alunos à desconstrução de exemplares de textos que instanciam gêneros cuja forma de estruturação eles mesmos utilizarão, posteriormente, em suas próprias produções (MARTIN e ROSE, 2012). Assim, o aluno aprenderá um pouco mais com o auxílio da leitura, importante recurso de ampliação do repertório para o desenvolvimento de temas sobre os quais se tem de escrever. Sob a perspectiva sociorretórica, a leitura pode ser usada para "apresentar novas oportunidades conversacionais que atraiam os alunos para comunidades públicas, profissionais e acadêmicas mais amplas. Assim, os alunos aprenderão a escrever dentro dos contextos altamente letrados que enfrentarão mais tarde na vida" (BAZERMAN, 2006, p.43).

A etapa de escrita, por sua vez, consiste no registro organizado das ideias e informações em forma de texto, pertencente a um gênero textual específico (SOARES, 2009).

A pós-escrita, por fim, envolve atividades que incluem um período de leitura e avaliação do que foi escrito e o recebimento de feedbacks (bilhetes orientadores, listas de controle, comentários orais) do professor ou de outros leitores sobre o conteúdo do texto para que o autor possa melhorá-lo (SOARES, 2009) e, por conseguinte, encaminhar o produto final para sua finalidade no meio social.

Mediante a implementação dessas etapas nas edições do Ateliê de Textos no contexto de atuação descrito na seção 3, e a partir das reflexões sobre os resultados obtidos, optamos por fazer uma adaptação nas duas últimas etapas (escrita e pós-

produção textual passa a ser em etapas, com diferentes oportunidades para revisões e reescritas, como veremos na seção 4 . 
escrita), por entendermos a revisão e a reescrita como processos recursivos, que recomeçam a cada nova versão do texto, como veremos na seção 4 .

\section{CONTEXTO DE ATUAÇÃO E PROCEDIMENTOS METODOLÓGICOS}

A proposta metodológica de ensino de produção textual que sistematizamos na seção 4 foi concebida a partir das atividades desenvolvidas em quatro edições do Ateliê de Textos, das quais participaram, voluntariamente, alunos das séries finais do Ensino Fundamental de quatro escolas públicas em Santa Maria, RS, cujos textos produzidos resultaram em três coletâneas de contos reinventados (Quadro 2).

Quadro 2 - Dados do contexto de atuação e implementação do Ateliê de Textos.

\begin{tabular}{|l|l|l|l|l|l|}
\hline Edição & Período & $\begin{array}{l}\text { Instituição de } \\
\text { ensino }\end{array}$ & Séries & $\begin{array}{l}\text { Alunos- } \\
\text { autores }\end{array}$ & Títulos das coletâneas \\
\hline $1^{\mathrm{a}}$ & $\begin{array}{l}\text { Ago. a } \\
\text { nov. 2011 }\end{array}$ & $\begin{array}{l}\text { Colégio Estadual } \\
\text { Profa. Edna May } \\
\text { Cardoso }\end{array}$ & $6^{\mathrm{a}}$ a $8^{\mathrm{a}}$ & 12 & Misturamos e deu nisso \\
\hline $2^{\mathrm{a}}$ & $\begin{array}{l}\text { Ago. a } \\
\text { dez. 2012 }\end{array}$ & $\begin{array}{l}\text { Escola Estadual } \\
\text { Marieta } \\
\text { D'Ambrósio }\end{array}$ & $6^{\mathrm{a}}$ a $7^{\mathrm{a}}$ & 17 & $\begin{array}{l}\text { Modernizando os } \\
\text { clássicos }\end{array}$ \\
\hline $3^{\mathrm{a}}$ & $\begin{array}{l}\text { Ago. a } \\
\text { dez. 2013 }\end{array}$ & $\begin{array}{l}\text { Escola Estadual } \\
\text { Celina de Moraes }\end{array}$ & $5^{\mathrm{a}}$ a $7^{\mathrm{a}}$ & 09 & $\begin{array}{l}\text { Contos e recontos: } \text { de } \\
\text { leitores a escritores }\end{array}$ \\
\hline $4^{\mathrm{a}}$ & $\begin{array}{l}\text { Ago. a } \\
\text { dez. 2013 }\end{array}$ & $\begin{array}{l}\text { Escola Estadual } \\
\text { Profa. Margarida } \\
\text { Lopes }\end{array}$ & $6^{\mathrm{a}}$ a $7^{\mathrm{a}}$ & 06 & $\begin{array}{l}\text { Contos e recontos: } \text { de } \\
\text { leitores a escritores }\end{array}$ \\
\hline
\end{tabular}

As ações do Ateliê de Textos são planejadas no primeiro semestre de cada ano e executadas no semestre seguinte na escola parceira. A equipe de trabalho é composta por acadêmicos de graduação e pós-graduação em Letras, orientados pela autora deste artigo, que também coordena o projeto. Nas escolas, o projeto conta com o apoio da direção, da coordenação pedagógica e de um professor de língua portuguesa que providencia a infraestrutura necessária à execução das atividades e acompanha o processo.

Os procedimentos realizados pela equipe para a implementação e execução do projeto envolvem:

- estudo das teorias que fundamentam as concepções de linguagem, texto, gênero e ensino de escrita;

- ações voltadas para o planejamento de atividades de leitura e produção de textos contextualizadas;

- elaboração de propostas de produção textual que explorem temáticas e situações de interação social pertinentes ao contexto dos seus potenciais autores (estudantes das séries finais do ensino fundamental), de modo a envolvê-los como

\footnotetext{
${ }^{7}$ Como a terceira e quarta edições foram realizadas no mesmo ano que, os textos dos alunos-autores foram reunidos na mesma coletânea, cujo lançamento foi realizada numa das escolas parceiras, com a presença de familiares e amigos dos autores das duas edições.
} 
agentes sociais, capazes de fazer uso da escrita para representar experiências, posicionar-se e promover mudanças em sua comunidade;

- realização de procedimentos de leitura e avaliação das diversas versões produzidas por esses alunos, tendo por base pressupostos das abordagens sociorretórica e sistêmico-funcional em associação com a perspectiva textual-interativa para orientar o processo de revisão e reescrita de cada versão;

- utilização de diferentes recursos para prover feedbacks aos alunos durante o processo de produção textual (bilhetes orientadores, orientações orais, listas de controle, feedback coletivo);

- organização de uma coletânea com as versões finais produzidas pelos alunosautores;

- organização da sessão de lançamento da obra, de modo a oportunizar aos participantes uma reflexão sobre seu processo de aprendizagem da escrita e sobre o papel da escrita na vida em sociedade.

Os alunos se inscrevem, voluntariamente, na oficina, cujos encontros ocorrem em sua escola, no turno inverso às aulas regulares. Em média, são realizados 12 encontros, com 2 horas semanais, totalizando em média 25 horas-aula, para atividades que se desenvolvem em etapas e culminam com a publicação de uma coletânea com os textos produzidos pelos participantes.

Na seção a seguir, apresentamos uma sistematização do processo de produção de narrativa (um dos gêneros do grupo das histórias, usadas para envolver o leitor, conforme a perspectiva da Escola de Sidney), desde as atividades preparatórias para a produção escrita até a socialização da versão final do texto produzido.

\section{SISTEMATIZAÇÃO DO PROCESSO DE PRODUÇÃO ESCRITA DO ATELIÊ DE TEXTOS}

Reflexões e avaliações sobre as atividades realizadas, bem como adaptações de estratégias e recursos utilizados nas quatro edições do Ateliê de Textos levaram-nos a produzir várias versões de uma sistematização do processo de produção de textos narrativos nas séries finais do ensino fundamental, ilustrada na Figura 1. Na sequência, são explicadas e exemplificadas as atividades concernentes a cada momento do processo. 
Figura 1 - Sistematização das etapas do processo de produção escrita no Ateliê de Textos

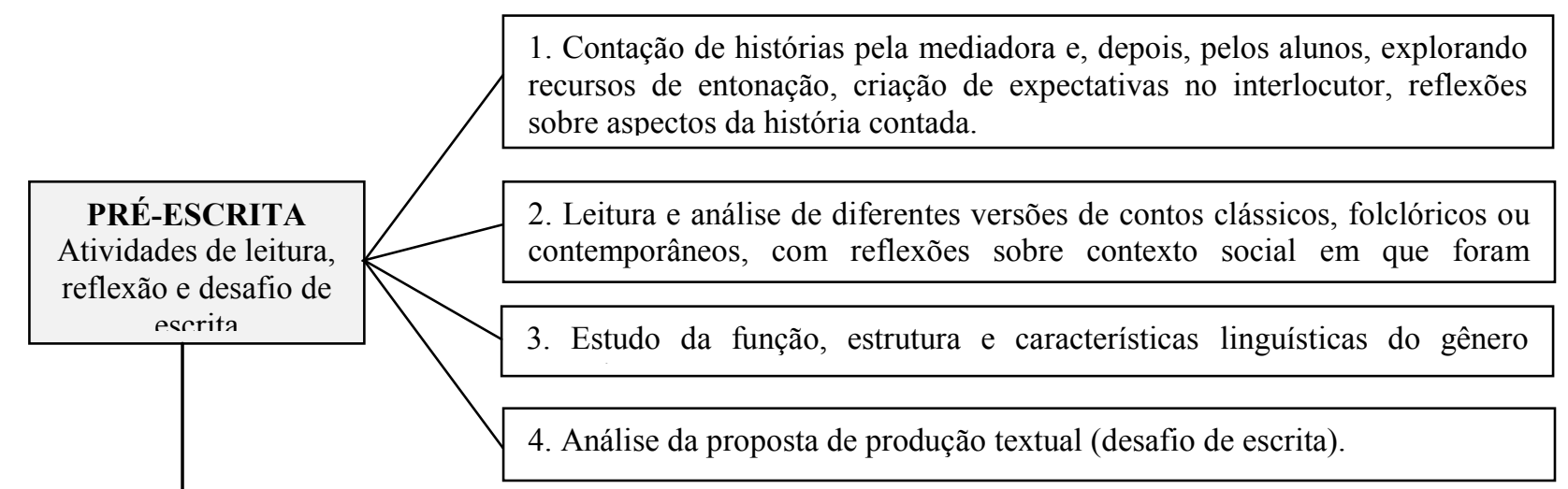

5. Produção individual: reinvenção de um conto à escolha do aluno.

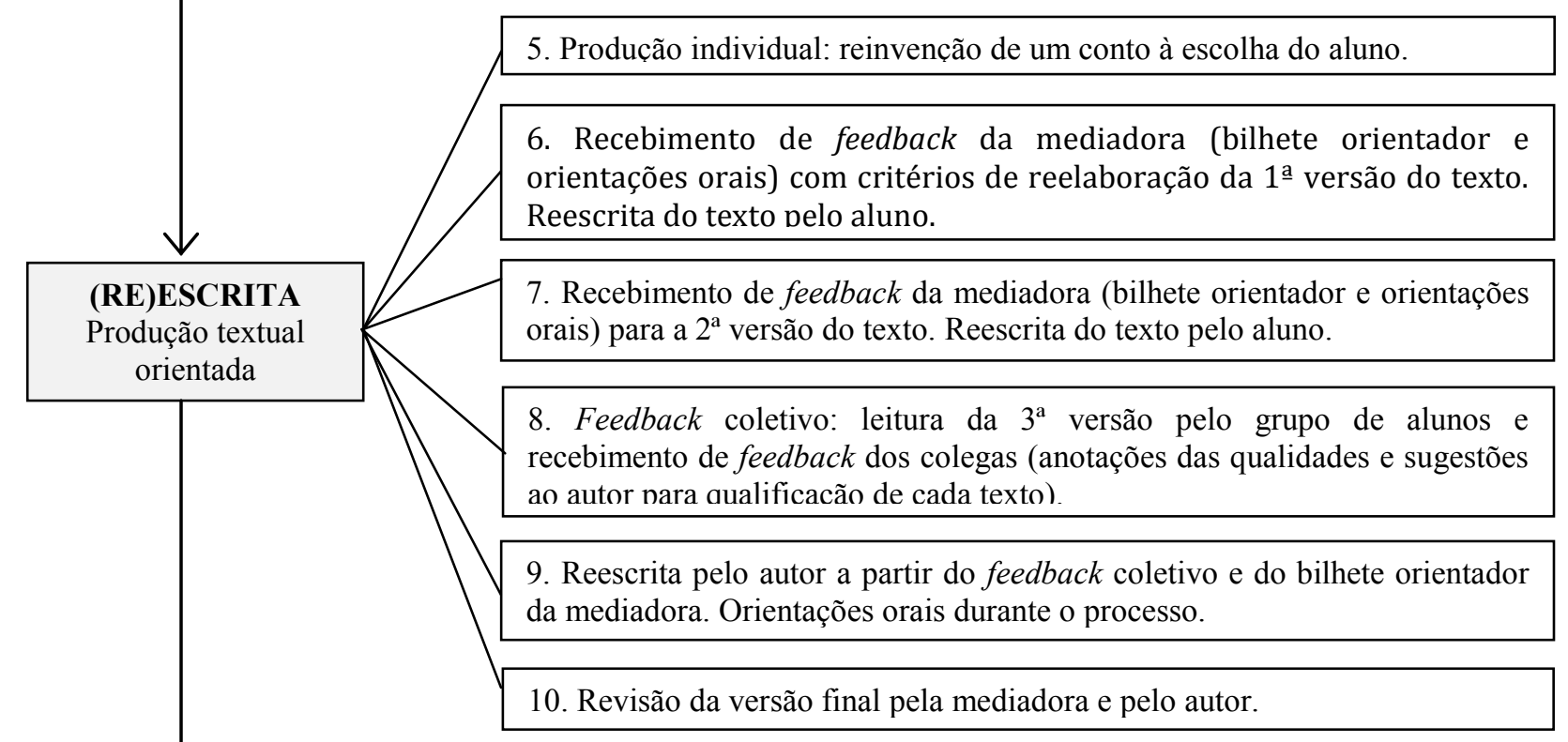

11. Digitação da versão final pelo autor em processador de texto no Laboratório de Informática.

12. Reunião com a equipe e os autores para editoração da coletânea (elaboração de título, agradecimentos, ilustrações, ficha catalográfica, diagramação) e organização da sessão de lançamento (cerimonial, convites).
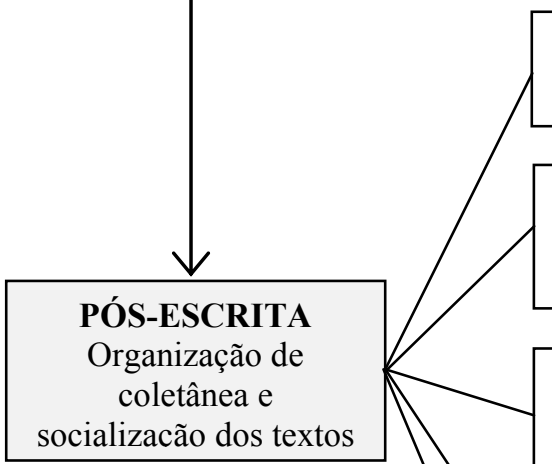

13. Socialização dos textos produzidos por meio de lançamento da coletânea na escola, com a presença dos convidados dos autores, professores da escola e equipe do Ateliê de Textos (cerimonial, sessão de autógrafos e confraternizacãก)

14. Notícias e registros fotográficos do lançamento em redes sociais, no site/blog/facebook da escola e no portal da universidade.

15. Doação de exemplares da coletânea aos autores, à biblioteca da escola e aos colaboradores. 


\subsection{Pré-escrita: atividades de leitura, reflexão e desafio de escrita}

Como primeira etapa do processo de produção textual aqui proposto, a préescrita se constitui de uma série de atividades de leitura, análise e reflexão, que visam a preparar o aluno para o momento da produção do seu próprio texto.

Ressaltamos que a sequência das atividades dessa etapa não é estanque; pode ser alterada conforme o contexto e os objetivos de ensino. Pode-se começar o trabalho, por exemplo, lançando o desafio de escrita aos alunos e, depois da análise e discussão da proposta, buscar informações sobre o gênero a ser utilizado (elementos caracterizadores), ler e analisar textos do mesmo gênero, ler textos de diferentes gêneros para ampliar repertório sobre o tema a ser abordado e finalizar com sessões de contação de histórias. Entretanto, a sequência de atividades de pré-escrita apresentada na Figura 1 tem se mostrado pertinente no contexto do Ateliê de Textos, em que a participação das oficinas é voluntária e, por isso, não parte da proposição de uma tarefa escolar obrigatória para fins de atribuição de notas ou conceitos.

Inicialmente, os alunos são convidados a falar sobre contos que já leram ou lhes contaram ou viram em filmes. Enquanto são compartilhados conhecimentos prévios, a mediadora ${ }^{8}$ anota os contos mencionados pelo grupo e pergunta sobre outros que não tenham sido citados. Com base nessa contextualização, o processo inicia com sessões de contação de histórias, escolhidas pelos alunos dentre os contos mencionados (item 1 na Figura 1). Aos interlocutores posicionados em círculo no ambiente, uma história é lida pela mediadora, com entonações e gestos que contribuem para a interação com os interlocutores e a imaginação das cenas representadas no texto. Os alunos também são convidados a levantarem hipóteses sobre razões para as personagens terem agido de determinado modo, apresentarem suas expectativas quanto à ação ou à cena seguinte do enredo ou quanto ao desfecho da história.

$\mathrm{Na}$ sequência, os alunos leem outra versão do mesmo conto, revezando-se na voz do narrador e das personagens. A mediadora então conduz uma discussão sobre semelhanças e diferenças entre as duas versões, explicando variáveis do contexto de produção de cada história (item 2 na Figura 1), como, por exemplo, a França barroca nos contos de fadas de Perrault, preocupado com a transmissão de valores morais e bons costumes, ou os principados alemães nos contos dos irmãos Grimm, preocupados com a sobrevivência, justiça e liberdade. Dessa forma, são disponibilizadas aos alunos diferentes versões de contos clássicos (como as de Perrault, dos Irmãos Grimm, de Andersen) e, por meio de exercícios de comparação, verificam-se as diferenças na caracterização das personagens (em termos de aparência, comportamento, personalidade), dos cenários, das avaliações e soluções apresentadas às complicações vivenciadas pelas personagens. A partir disso, são conduzidas reflexões e discussões sobre posturas, costumes e valores sociais representados nos textos de cada autor, de modo a sensibilizar os alunos-leitores acerca da influência de variáveis do contexto de situação e de cultura (nos termos de HALLIDAY, 1989) na produção de significados nos textos que leem. Ao mesmo tempo, busca-se levá-los a compreensão de como o seu contexto social influencia na produção de significados de seus próprios textos, o que

\footnotetext{
${ }^{8}$ No contexto do Ateliê de Textos, o papel de mediador, entendido como aquele que faz a ponte entre o texto e o leitor, é exercido por uma das acadêmicas do curso de Licenciatura em Letras que integra a equipe de trabalho.
} 
vivenciarão mais diretamente na etapa de (re)escrita, e o quanto a consciência dessa influência colabora para a produção de textos mais qualificados.

Com a leitura e análise contextual de exemplares do mesmo gênero, encaminha-se o estudo do gênero (item 3 na Figura 1), fornecendo aos alunos subsídios para a compreensão sua estrutura composicional (tendo em vista a função e a constituição linguística dos estágios do texto), seus recursos linguísticos e discursivos para a construção de narrador e personagens, diálogos, relações de tempo e espaço ${ }^{9}$. Isso não significa que os alunos tenham de reproduzir ou imitar um "modelo", e sim, como argumenta Passarelli (2012, p.55), ter um ponto de partida ou "(re)criá-lo".

Sob a perspectiva da reinvenção, é lançado o desafio de escrita (item 4 na Figura 1), inspirado nesta questão: "contos de fadas aceitam novas versões, de acordo com o estilo do autor e o contexto em que a história foi produzida. Como seria a sua versão da história hoje?" (adaptada de CANTON, 2009). No trabalho com contos clássicos da literatura infantil, é proposta a reinvenção de um conto a ser escolhido pelo aluno, tendo em vista a situação comunicativa e as condições de interlocução explicitadas na proposta de produção textual (Anexo1). Tendo por princípio que o professor também tem de "redigir textos claros e coerentes para que os alunos fiquem de fato orientados quando forem produzir seus textos" (PASSARELLI, 2012, p.137), a proposta é entregue por escrito aos alunos, para que possam recorrer às instruções sempre que sentirem necessidade durante seu processo de produção.

Tendo em vista que "cada narrativa, em sua versão singular, agrega em si valores particulares, ligados à história e ao contexto do autor que a escreveu ou transcreveu, somados a valores universais que estão na espinha dorsal e na estrutura desse conto" (CANTON, 2009, p.16), a proposta de reinvenção de contos contém listas de palavras que sugerem histórias conhecidas pelos alunos; algumas das palavras, porém, representam um elemento novo, destoante, que permite a recontextualização do conto, como exemplificam os elementos em destaque nestes exemplos: 1) Cinderela, madrasta, príncipe, sapatinho de cristal, chulé; 2) Chapeuzinho Vermelho, bosque, lobo, avó, helicóptero; 3) Rapunzel, torre Eiffel, príncipe, bruxa, cabeleireiro; 4) Patinho Feio, óculos, Facebook, cisne. ${ }^{10}$

Realizada a interpretação da proposta e as escolhas que cabem aos alunos ${ }^{11}$, realiza-se a escrita propriamente dita (item 5 na Figura 1), seguida de revisões e reescritas orientadas por meio de feedbacks, o que se apresenta na subseção a seguir.

\section{$3.2(\operatorname{Re})$ escrita: produção textual orientada}

Em sala de aula, cada aluno reinventa um conto clássico a partir do seu contexto social e estilo pessoal (item 5 na Figura 1). A primeira versão do texto, mesmo que incompleta, é entregue no final do encontro ao mediador, que fornece, nas semanas

\footnotetext{
${ }^{9}$ Além da sistematização das características do gênero narrativa realizada pelo grupo da Escola de Sidney (ROSE e MARTIN, 2012), destacamos o trabalho de Soares (2010), que apresenta de forma didática instruções para a criação de narrativas por escritores iniciantes.

${ }^{10}$ Em cada lista, que se refere a um conto clássico, elementos destoantes podem ser acrescentados ou substituídos por outros que remetam ao contexto social do aluno.

${ }^{11}$ Ao possibilitar a escolha do tema, do gênero, da audiência e, neste caso, do conto a ser reinventado a partir da seleção de uma das listas oferecidas é parte do processo de escrita, o professor delega ao aluno a responsabilidade pelo que escrevem, oportunidade que, segundo Passarelli (2012:61), "transforma o ato de escrever de uma tarefa designada a um projeto pessoal".
} 
seguintes, feedbacks individuais e coletivos (itens 6, 7 e 8) para auxiliar na revisão e orientar a reescrita (itens 9 e 10 na Figura 1).

Antes de detalharmos o funcionamento dessa etapa do processo de produção textual, convém explicarmos que a alteração da denominação "escrita" (apresentada em SOARES, 2009) para "(re)escrita" deve-se ao nosso entendimento da escrita como um processo recursivo, que se constitui não só do ato de escrever em si, mas também das sucessivas revisões interativas e reescritas que visam ao aprimoramento do texto por meio de transformações de conteúdo e forma, até que o produto decorrente desse processo (o texto em sua última versão) possa ser considerado satisfatório aos critérios adotados na fase de pré-escrita. Dessa forma, a etapa de (re)escrita engloba as diversas versões geradas ao longo do trabalho de produção e revisão pelo aluno com o auxílio de feedbacks pelo mediador e pelos colegas em diferentes momentos do processo, dando ao aluno oportunidades de "explicitar seus conhecimentos e suas dúvidas, procurar soluções, raciocinar sobre o funcionamento da língua e, assim, desenvolver a aprendizagem e questões linguísticas, textuais e discursivas mais complexas referentes à modalidade escrita" (GONÇALVES, 2013, p.40).

Diante dessa adaptação na forma de organizar as etapas do processo de produção textual, ocorrem, na etapa de (re)escrita, intervenções colaborativas não só do mediador por meio de recursos didáticos (explicitação de critérios de avaliação, bilhetes orientadores e orientações orais), como também dos colegas por meio de feedbacks coletivos.

Dentre os recursos usados pelo mediador, os critérios (Anexo 2), definidos com base na função e nos traços tipificadores do gênero em uso, auxiliam a reelaboração textual (LEITE e PEREIRA, 2013). São avaliados a adequação do texto à proposta de produção, os aspectos de coesão e coerência, a estrutura e os elementos da narrativa, bem como o uso adequado da linguagem na modalidade escrita. Ao empenhar-se para que seu texto atenda a esses critérios que explicitam características do gênero, o produtor retoma aspectos composicionais e linguísticos estudados na etapa de préescrita.

O bilhete orientador, por sua vez, é usado como um espaço de interação, em que o mediador se coloca na posição de leitor interessado na história produzida pelo aluno e, ao mesmo tempo, produtor de um texto que tem como uma das finalidades auxiliar no processo de reescrita dessa história. O aluno, por sua vez, torna-se leitor do texto produzido pelo professor e também pode reagir a esse texto no momento da reescrita da sua própria história, esforçando-se para atender às orientações propostas, ou optando por alterar seu projeto de escrita, ou até mesmo mantendo sua escolha inicial (quanto a características de algum personagem, a um detalhe do cenário ou à troca de palavras).

A prática de elaboração, revisão e reelaboração de uma série de bilhetes orientadores ao longo das edições do Ateliê de Textos e a análise de um conjunto de bilhetes com as respectivas versões de textos produzidos por alunos (FUZER e WEBER, 2012; FUZER, 2012) possibilitaram uma sistematização da organização retórica do bilhete orientador (Quadro 3), que tem sido usada para auxiliar na formação de professores de produção textual. 
Quadro 3 - Organização retórica do bilhete orientador (adaptada de FUZER, 2012)

\begin{tabular}{|l|l|}
\hline \multicolumn{1}{|c|}{ Movimentos } & \multicolumn{1}{c|}{ Passos } \\
\hline 1. Reações do leitor ao texto do & 1.1 Estabelecimento de contato e/ou \\
aluno & 1.2 Manifestação de opinião sobre o texto \\
\hline \multirow{3}{*}{ 2. Elogios à produção } & 2.1 Elogios ao aluno e/ou \\
& 2.2 Elogios ao texto em geral e/ou \\
& 2.3 Elogios a aspectos do texto \\
\hline \multirow{3}{*}{ 3. Orientações para a reescrita } & 3.1 Sugestões para qualificação de conteúdo e \\
& 3.2 Sugestões para ajustes na estrutura textual e \\
& expressão linguística \\
\hline \multirow{2}{*}{ 4. Incentivo à reescrita } & 4.1 Incentivo à continuação do processo e/ou \\
& 4.2 Expectativas quanto à próxima versão \\
\hline
\end{tabular}

Antes da entrega, porém, o bilhete é revisado pela equipe de acadêmicos e professores do Ateliê de Textos, que se reúne semanalmente, na universidade, para refletir sobre cada momento do processo, avaliar cada ação realizada, detectar nos textos as principais dificuldades de leitura e escrita, elaborar listas de controle para eleger questões a serem trabalhadas coletivamente e pensar em estratégias de assistência para a reescrita de cada texto pelo seu autor. O bilhete orientador é considerado um espaço especial de interação entre um leitor mais experiente e o produtor do texto (SIGNORINI, 2006). Por isso, os bilhetes são personalizados e pode ser organizado conforme os movimentos e passos propostos no Quadro 3.

São fornecidos bilhetes orientadores para cada aluno-autor, em quantidade proporcional ao número de versões produzidas, numa sistemática que passamos a descrever a seguir. A primeira versão do texto é devolvida ao aluno-autor, que a relê após um período de distanciamento. Na sequência, a mediadora explica para o grupo a função do bilhete orientador e sua organização - gênero textual muitas vezes novo para os alunos. Depois disso, cada aluno recebe um bilhete orientador com comentários positivos sobre sua produção, sugestões e perguntas que o provocam a refletir sobre determinados aspectos, para que busque fornecer informações mais específicas em passagens que não estão suficientemente claras, repensar determinada situação retratada na história inicial, revisar usos da linguagem, dentre outros aspectos que vão surgindo à medida que o processo de (re)leitura e (re)escrita transcorre. Nesse primeiro bilhete, é conveniente dar mais atenção a questões de conteúdo do texto do que a questões formais, para que a concentração do aluno esteja direcionada ao tema e ao enredo da sua história.

A mediação da leitura do bilhete orientador é feita também individualmente, a partir dos itens em que o aluno manifesta necessidade de maior assistência. Esse processo ocorre, pelo menos, três vezes na sequência dos encontros. Assim como a primeira, a segunda e terceira versões do texto são devolvidas ao aluno-autor com outros bilhetes orientadores e, se necessário, materiais para leitura de apoio ou instruções para pesquisa. O bilhete orientador funciona, portanto, como "um andaime para a aprendizagem de práticas de escrita" (NASCIMENTO, 2013, p.65), haja vista seu caráter personalizado no reconhecimento de aspectos positivos e no oferecimento de "simpáticos conselhos sobre como fazer em vez de o que não fazer" (BAZERMAN, 2006, p.36). 
Listas de controle também são utilizadas na etapa de (re)escrita para mapear problemas de compreensão e escrita que se mostram recorrentes nos textos do grupo de alunos e, com base nos apontamentos, são fornecidas orientações orais coletivas. Nessa fase, também é utilizado o feedback coletivo, em que os colegas do aluno-autor manifestam reações aos textos. Para isso, o grupo é orientado a ler e ouvir o texto do colega e manifestar sua opinião sobre a história, começando sempre por elogios ao que considerou bom e, depois, apresentando sugestões para o que acredita que poderia tornar a história mais clara e interessante. Cada autor é convidado a ler seu próprio texto ou autorizar que outra pessoa leia, a ouvir os comentários dos colegas ${ }^{12} \mathrm{e}$, depois, no momento da reescrita, a decidir o que alterará ou não na sua terceira versão.

\subsection{Pós-escrita: organização de coletânea e socialização dos textos produzidos}

Por consequência da compreensão da escrita como um processo recursivo, a terceira etapa (pós-escrita) passa a ser concebida não mais como uma ocasião para revisão e recebimento de feedback, pois isso já foi feito na etapa de (re)escrita, mas como uma oportunidade de socialização do produto (a versão final do texto). Essa etapa propicia a interação do aluno-autor, via texto, com outros leitores fora do contexto escolar, tendo em vista o gênero utilizado e o suporte em que poderá ser veiculado (jornal, livro, blog, revista, etc.). Nessa etapa, temos em conta que, "antes de ser um objeto escolar, a escrita é um objeto social (...). Daí a relevância de aproximar os usos escolares da língua escrita com o aspecto comunicativo dentro e fora do contexto escolar" (PASSARELLI, 2012, p.116). No caso do Ateliê de Textos, essa etapa concretiza-se com a organização de uma coletânea de contos (Anexo 3), que é publicada e lançada com sessão de autógrafos diante de amigos e familiares dos autores.

$\mathrm{O}$ encaminhamento da etapa de pós-escrita ocorre quando os alunos-autores são levados ao laboratório de informática da escola para que cada um digite a versão final do seu texto (item 11 na Figura 1). Ainda podem fazer ajustes pontuais, principalmente quanto a aspectos formais de escrita, com o auxílio do mediador. Como alguns alunos não têm habilidade com o processador de textos nem com o teclado do computador, esse momento configura-se também numa oportunidade para aprender a usar esse recurso tecnológico, o que contribui, mesmo que de modo singelo, para a inclusão digital desses jovens no contexto da escola pública.

Nessa etapa, cada aluno ainda é convidado a ilustrar sua história, sendo incentivado a destacar alguma passagem que considere importante, usando diferentes materiais e métodos (sempre que possível, o professor de artes da escola é convidado a auxiliá-los nesse processo). As ilustrações são escaneadas e incluídas num livreto, que é diagramado e impresso pela equipe do Ateliê de Textos. Os alunos participam de todas as decisões concernentes ao livreto, desde a elaboração do título (como "Misturamos e deu nisso", "Modernizando os clássicos", "Contos e recontos: de leitores a escritores") até a ilustração da capa, a elaboração da dedicatória e dos agradecimentos, a disposição das ilustrações e dos textos nas páginas (item 12 na Figura 1).

\footnotetext{
${ }^{12}$ Antes de iniciar a atividade, o mediador solicita aos alunos que vão anotando numa folha, em um lado, os aspectos positivos que forem sendo manifestados e, no outro lado, as sugestões dadas pelo grupo para ajudar a qualificar o texto. Ao final da atividade, o mediador recolhe as anotações para selecionar as que estiverem mais claras, como memórias do feedback coletivo. $\mathrm{Na}$ aula seguinte, o mediador entrega ao aluno-autor essas anotações anexadas à versão do texto que será reescrito novamente.
} 
O último encontro é uma confraternização entre os autores, seus familiares, amigos, professores e demais convidados, para o lançamento da coletânea (item 13 na Figura 1), que é divulgada na comunidade escolar e universitária (item 14 na Figura 1). Os livretos são doados aos autores para que presenteiem seus convidados; alguns exemplares são ainda doados à biblioteca da escola e aos professores que contribuíram direta ou indiretamente com aquela edição do Ateliê de Textos (item 15 na Figura 1). Nesse contexto, como observa Bazerman (2006, p.18),

mesmo se a escrita imaginativa não chega aos padrões de trabalhos profissionais publicados, tem um valor especial se é feita e compartilhada por pessoas familiares umas com as outras. Se colegas, família e amigos constituem a audiência, a escrita constrói identidade, relações e compreensão mútua.

Esse papel da escrita se verifica na ocasião do lançamento da sua obra, em que é visível o entusiasmo dos jovens autores ao autografarem os livretos de contos que foram relidos/reinventados numa adaptação para o mundo contemporâneo. Na coletânea, o leitor verá que

\begin{abstract}
as personagens que encantaram várias gerações aparecem num contexto atualizado. Rapunzel usa 'aplic'; a bruxa é dona de um restaurante em Paris; Branca de Neve frequenta baile funk; uma Cinderela vai a uma 'rave', enquanto outra se casa com o filho do prefeito; a vovó de Chapeuzinho pilota helicóptero... Já uma Bela Adormecida é fã de Guns N'Roses e outra, pasmem, é 'emo', e sua desventura não é efeito da maldição de uma fada má, mas de macumba! (CELIDÔNIO, 2011, p.5)
\end{abstract}

Assim, as personagens clássicas ganham personalidades semelhantes à de um adolescente de hoje e vivem num mundo que nos parece bem atual - como a Chapeuzinho dos olhos vermelhos que passava horas em frente ao computador, e outra que tocava rock numa guitarra vermelha; dois irmãos que conseguiram voltar para casa usando o GPS da bruxa; a Branca de Neve que usava um vestido igual ao da Lady Gaga; os três porquinhos que usaram recursos do Fundo de Garantia por Tempo de Serviço para construir suas casas na praia. Nesse processo, "percebe-se o quanto os autores esforçaram-se para assumir o ponto de vista e a maneira de pensar de outras personagens e, ao mesmo tempo, projetaram nelas os seus próprios anseios e fantasias" (TRENTIN, 2012, p.6).

Isso demonstra o que Bazerman (2006) pondera: quando se estabelece a voz do escritor (sua posição retórica) e a autoridade da percepção pessoal, o professor aprende a valorizar o que aluno quer dizer e a ser paciente com o processo complexo da escrita.

\title{
4 CONSIDERAÇÕES FINAIS
}

O trabalho com a escrita de textos como processo e como produto, conforme apresentado neste artigo, tem demonstrado que produzindo textos, revisando com auxílio de feedbacks e reescrevendo, quantas vezes forem necessárias, o aluno-autor melhora não só seu desempenho no uso de recursos da linguagem de acordo com o gênero textual produzido, como também a consciência do seu papel no processo de produção. Ao longo desse processo, revisão e reescrita se complementam, uma vez que, "por meio da revisão, o autor analisa seu produto, reflete a respeito dos elementos 
escolhidos, observando se suas escolhas colaboram para que seus objetivos sejam atingidos" (MENEGASSI, 2013, p.111).

Com a sistemática de trabalho apresentada aqui, os alunos vão percebendo que várias decisões precisam ser tomadas durante a produção de um texto, dependendo das reações que se espera provocar nos potenciais leitores. Ao longo das atividades de préescrita, (re)escrita e pós-escrita, realizadas no Ateliê de Textos, os alunos-autores do ensino básico aprendem a valorizar a interação com outras pessoas (mediador, colegas de oficina e integrantes da equipe) para alcançar um propósito comum: ter seus textos, produzidos com tanto empenho, socializados em forma de livro na sua comunidade. $\mathrm{O}$ lançamento da coletânea de contos reinventados a partir de clássicos da literatura infantil é a culminância de um processo que demanda a mobilização de conhecimentos prévios sobre o mundo e a linguagem, capacidade imaginativa, compreensão de variáveis contextuais, além de outros tantos conhecimentos e habilidades que vão sendo desenvolvidas no decorrer das atividades organizadas em etapas.

Assim, além de conduzir o aluno-autor "para a produção de versões cada vez mais semelhantes ao gênero de referência" (NASCIMENTO, 2013, p.80), contribui-se para a descoberta de motivações pessoais para aprender a escrever.

\section{REFERÊNCIAS BIBLIOGRÁFICAS}

BAZERMAN, C. Gênero, agência e escrita. Tradução de Judith Chambliss Hoffnagel. São Paulo: Cortez, 2006.

Gêneros textuais, tipificação e interação. Tradução e organização de Angela Paiva Dionísio e Judith Chambliss Hoffnagel. São Paulo: Cortez, 2005.

BUIN, E. O impacto do bilhete do professor na construção do sentido do texto do aluno. In: SIGNORINI, I. (Org.). Gêneros catalisadores: letramento e formação do professor. São Paulo: Parábola, 2006. p. 95-124.

CANTON, K. Os contos de fadas e a arte. São Paulo: Prumo, 2009.

CELIDÔNIO, E. Prefácio. In: MACHADO, A.Y.C. et al. Misturamos e deu nisso. Santa Maria: DLV, CAL, UFSM, Colégio Edna May Cardoso, 2011.

DICIONÁRIO PRIBERAM DA LÍNGUA PORTUGUESA, 2008-2013. Disponível em: http://www.priberam.pt/dlpo/ateli\%C3\%AA. Acesso em: 20 fev. 2014.

FEUERSTEIN, R. The theory of structural cognitive modifiability. In: PRESSEISEN, B. (Ed.) Learning and thinking styles: classroom interaction. Washington, DC: National Education Association, 1990. p. 68-134.

FLOWER, L.; HAYES, J. A cognitive process theory of writing. College Composition and Communication, v. 32, p. 365-387, 1981.

FUZER, C. Bilhete orientador como instrumento de interação no processo ensinoaprendizagem de produção textual. Revista Letras, v. 22, n. 44, p. 213-245, 2012. Disponível em: http://w3.ufsm.br/revistaletras/artigos_r44/artigo_10.pdf 
; WEBER, Taciane. Um passo de cada vez. a (re)escrita em resposta a feedbacks no processo ensino-aprendizagem de produção textual. Cadernos de Linguagem \& Sociedade, v. 13, n. 2, p. 36-60, 2012. Disponível em: http://seer.bce.unb.br/index.php/les/article/view/7872/6000

FREEDMAN, A.; MEDWAY, P. Genre and the New Rhetoric. London: Taylor e Francis, 1994.

GERALDI, J.W. A produção de textos. In: .Portos de passagem. 2. ed. São Paulo: Martins Fontes, 1993. p. 135-165.

GONÇALVES, A.V.; BAZARIM, M. (Orgs.). Interação, gêneros e letramento: a (re)escrita em foco. São Carlos: Claraluz, 2009.

GOUVEIA, C.M. A formação de professores e o desenvolvimento da literacia: contributos dos estudos de género para a docência e aprendizagem colaborativa. In: SEMINÁRIO INTERNACIONAL EM LETRAS, 13, 11-14 jun. 2013, Santa Maria, RS (não publicado).

HALLIDAY, M.A.K. An Introduction to Functional Grammar. 2. ed., London: Arnold, 1994.

. An Introduction to Functional Grammar. 1. ed., London: Arnold, 1985.

HALLIDAY, M.A.K; HASAN, R. Language, context, and text: aspects of language in a social-semiotic perspective. Oxford: Oxford University Press, 1989.

HALLIDAY, M.A.K.; MATTHIESSEN, C.M.I.M. An Introduction to Functional Grammar. 4. ed., London and New York: Routledge, 2014.

HALLIDAY, M.A.K.; MATTHIESSEN, C.M.I.M. An Introduction to Functional Grammar. 3. ed., London: Arnold, 2004.

HOUAISS, A. Dicionário Houaiss da Língua Portuguesa. Rio de Janeiro: Objetiva, 2001.

LEITE, E.G.; PEREIRA, R.C.M. Implicações da correção do professor na reescrita do aluno: desenvolvendo as capacidades de linguagem. In: GONÇALVES, A. V.;

BAZARIM, M. (Orgs.). Interação, gêneros e letramento: a (re)escrita em foco. 2. ed. Campinas, SP: Pontes, 2013. p. 37-64.

MENEGASSI, R.J. A revisão de textos na formação docente inicial. In: GONÇALVES, A. V.; BAZARIM, M. (Orgs.). Interação, gêneros e letramento: a (re)escrita em foco. 2. ed. Campinas, SP: Pontes, 2013. p. 105-131.

. Da revisão a reescrita: operações e níveis linguísticos na construção do texto. 1998. 263 f. Tese (Doutorado) - Programa de Pós-Graduação em Letras, Universidade Estadual Paulista, Assis-SP, 1998. 
MILLER, C. Genre as social action. Quarterly Journal of Speech, n. 70, p. 151-167, 1984.

MOTTA-ROTH, D. Ensino de produção textual com base em atividades sociais e gêneros textuais. Linguagem em (Dis)curso - LemD, Tubarão, v. 6, n. 3, p. 495-517, set./dez. 2006.

NASCIMENTO, C.E. Os bilhetes orientadores da reescrita e a aprendizagem do gênero relatório de experiência. In: GONÇALVES, A. V.; BAZARIM, M. (Orgs.). Interação, gêneros e letramento: a (re)escrita em foco. 2. ed. Campinas, SP: Pontes, 2013. p. 6581 .

PASSARELLI, L.M.G. Ensino e correção na produção de textos escolares. São Paulo: Cortez, 2012.

PENTEADO, A.E.A.; MESKO, W.S. Como se responde a um bilhete? Movimentos a partir desse instrumento de intervenção nas produções textuais em processo de reescrita. In: SIGNORINI, I. (Org.). Gêneros catalisadores: letramento e formação do professor. São Paulo: Parábola, 2006.p. 95-124.

PRÊMIO RBS DE EDUCAÇÃO. Para entender o mundo. 2013. Disponível em: < http://www.premiorbsdeeducacao.com.br/premiados > Acesso em: 27 fev. 2014.

ROSE, D.; MARTIN, J. R. Learning to Write, Reading to Learn: Genre, Knowledge and Pedagogy in the Sydney School. London: Equinox, 2012.

RUIZ, E.D. Como corrigir redações na escola: uma proposta textual-interativa. São Paulo: Contexto, 2010.

SCHNEUWLY, B. Gêneros e tipos de discurso: considerações psicológicas e ontogenéticas. In: SCHNEUWLY, B.; DOLZ, J. Gêneros orais e escritos na escola. Tradução e organização Roxane Rojo e Glaís Sales Cordeiro. Campinas: Mercado de Letras, 2004, p. 21-40.

SCARDAMALIA, M.; BEREITER, C. Knowledge telling and knowledge transforming in written composition. In: ROSENBERG, S. (ed.). Advances in Applied

Psycolinguistics. v.2, Reading, Writing and Language Learning. Cambridge: Cambridge University Press, 1987. p. 142-175.

SIGNORINI, I. (Org.). Gêneros catalisadores: letramento e formação de professor. São Paulo: Parábola, 2006.

SILVA, W.R.; ESPINDOLA, E. Afinal, o que é gênero textual na linguística sistêmicofuncional? Revista da Anpoll, Florianópolis, n.34, p. 259-307, Jan./Jun. 2013.

SOARES, D. A. Produção textual e revisão textual: um guia para professores de português e de línguas estrangeiras. Petrópolis, RJ: Vozes, 2009. 
SOARES, E. P. A arte de escrever histórias. Barueri, SP: Manole, 2010.

TRENTIN, R. Prefácio. In: WENDT, A.F. et al. Modernizando os clássicos. Santa Maria: DLV, UFSM, CAL, Escola Estadual de Ensino Fundamental Marieta D'Ambrósio, 2012.

VYGOTSKY, L.S. A formação social da mente. 4.ed. São Paulo: Martins Fontes, 1991.

Recebido em: 05 de março de 2014.

Aceito em: 07 de maio de 2014. 


\section{ANEXOS}

Anexo 1 - Proposta de produção de texto narrativo (versão usada na $4^{\mathrm{a}}$ edição do Ateliê de Textos)

\section{PROPOSTA DE PRODUÇÃO DE TEXTO}

Imaginar é sempre muito divertido! Por isso, convidamos você a usar sua imaginação escrevendo um conto maravilhoso. Para isso, procure seguir as orientações abaixo.

a) Em cada lista de palavras abaixo, algumas palavras sugerem uma história conhecida, outras representam novos elementos, que quebram, de propósito, a sequência. Veja:

- Chapeuzinho Vermelho - lobo - vovó - ônibus - Três Barras

- Cinderela - fandango (baile) - madrasta - chimarrão

- Os Três Porquinhos - Universidade - lobo - asma - chaminé

- Rapunzel - Morro das Antenas - príncipe - bruxa - dreads

- João e Maria - confeitaria - bruxa - manifestação de rua

- Patinho feio - óculos - facebook - cisne

b) Escolha uma lista e reinvente a história, incluindo, nos acontecimentos, o novo elemento correspondente à palavra que destoa das outras. Escolha quem será o herói e quem fará o papel de vilão. Procure criar um final inesperado, se possível engraçado.

c) Planeje como vai ser o seu conto maravilhoso: inicie-o pela expressão "Era uma vez" ou outra que conduza a um tempo passado e impreciso. O narrador pode ser do tipo observador ou também um personagem. Lembre-se de dizer como são o herói e o vilão, e o lugar onde ocorrem os fatos. Ao terminar, dê um título sugestivo a seu conto.

d) Faça um rascunho e só passe seu conto a limpo depois de fazer uma revisão cuidadosa. Refaça quantas vezes forem necessárias.

e) Entregue o texto à professora, para que seja lido pela equipe do Ateliê de Textos que, se necessário, buscará ajudá-lo a tornar seu texto ainda melhor.

f) Em sua versão final, os textos serão publicados em uma coletânea de contos, cujo título será escolhido por você e seus colegas.

g) Faça uma ilustração bem bonita para seu conto.

Anexo 2 - Critérios para revisão e avaliação de narrativa

1- O texto está de acordo com a proposta.

2- $\mathrm{O}$ texto apresenta os elementos da narrativa: enredo, narrador, personagem, cenário e tempo.

3- O texto está organizado nos estágios: orientação, complicação, avaliação e resolução.

4- Elementos coesivos e marcas de discurso direto e/ou indireto são usados adequadamente.

5- $\mathrm{O}$ texto atende às normas linguísticas convencionais da modalidade escrita. 
Anexo 3 - Capas das coletâneas de contos reinventados produzidos nas edições do Ateliê de Textos

\section{EDIÇÃO 2011}

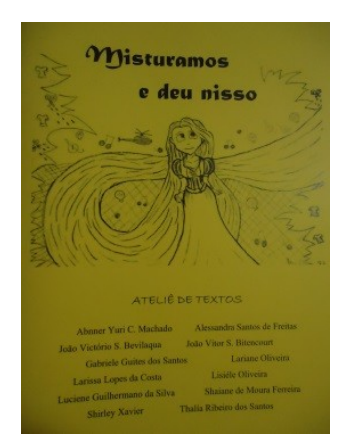

EDIÇÃO 2012

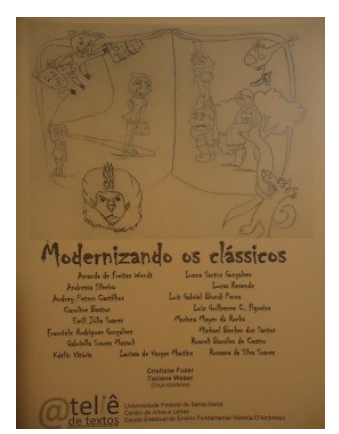

EDIÇÕES 2013

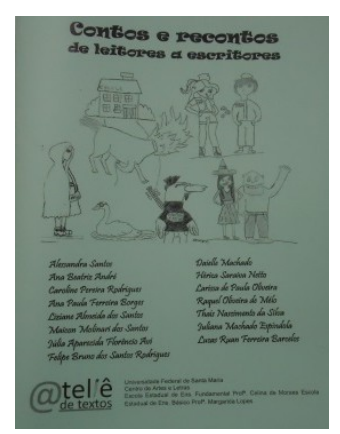

